\title{
Trajetórias de Mulheres HIV+ No Movimento Político de HIV/Aids no Estado do Paraná
}

\section{Carolina Branco de Castro Ferreira ${ }^{1}$}

\section{Resumo}

Este artigo tem como objetivo apreender, a partir da análise da experiência da doença e da trajetória de vida, as mudanças ocorridas na vida de mulheres HIV+ do Estado do Paraná depois de sua inserção no movimento político de HIV/Aids desse estado. Visa, ainda, entender as motivações que as levaram a se mobilizar e a forma como a perspectiva de gênero na experiência da doença interfere nessas motivações e na sua forma de atuação política. Tendo-se como pressuposto teórico-metodológico a abordagem antropológica da narrativa como forma de interpretação da experiência individual e coletiva, foram realizadas entrevistas em profundidade com 13 mulheres HIV+. Nas narrativas desponta, como categoria privilegiada de análise, a noção de pessoa, a qual é constituída por três aspectos diferenciados e, ao mesmo tempo, imbricados: a preeminência do todo, e não do indivíduo; a corporalidade; e a participação política. Esses aspectos estão articulados ao gênero, e este, por sua vez, à dimensão política, o que dá contornos específicos ao ativismo dessas mulheres.

Palavras-chave: Mulher, AIDS, participação política.

\section{Abstract}

This article aims at understanding changes in the lives of HIV + women in Paraná State after their insertion into political HIV/Aids activism, the motivations that led them to mobilization, and how gender perspective in experiencing this disease interferes with their motivations and political attitudes. Theoretically and methodologically drawing on the anthropological approach of the narrative as a form of interpretation of individual and collective experience, interviews with 13 HIV + women were accomplished and analyzed. The narratives reveal the notion of the person as a privileged category which consists of three distinguished though imbricated aspects: the person related to preeminence values of the whole and not the individual, embodiment and political participation. Such aspects are articulated with gender and gender is linked to a political dimension, which gives specific contours to these women's activism.

Keywords: Woman, AIDS, political participation.

1 Professora e pesquisadora da Universidade Estadual de Londrina, Mestre em Ciências Sociais por esta instituição e-mail: carolbranco@uel.br 


\section{Mulheres em Movimento}

$\mathrm{N}$ este artigo, faço uma reflexão sobre as mulheres HIV+ que participam do movimento político de HIV/Aids no Estado do Paraná tendo como objetivos apreender as mudanças ocorridas em suas vidas depois da inserção nesse movimento; entender as motivações que as levaram a se mobilizar; e compreender como a perspectiva de gênero na experiência da doença interfere nessas motivações e na sua forma de atuação política. Os pressupostos teóricos desta pesquisa basearam-se na bibliografia (MACHADO, 1995; SOARES, 1998) que aponta para as transformações que a participação das mulheres em movimentos sociais urbanos acarreta em suas vidas, pois elas modificam "parcialmente por meio de sua inserção nas comunidades, o uso de seu tempo" e, além disso, ampliam "seu espaço de circulação geográfico e social, suas trocas com outras mulheres, seu ativismo religioso e sua militância política", ou seja, transformam seu cotidiano (NUNES ROSADO apud SOARES, 1998, p. 40). Para entender a participação das mulheres HIV+, mediada pela experiência da doença, me baseio na literatura antropológica que considera os processos de saúde/doença como resultado da articulação entre o biológico, o cultural e a experiência subjetiva (AUGÉ, 1991; AUGÉ; HERZLICH, 1991; MONTERO, 1986; JEOLÁS, 1999; ADAM; HERZLICH, 2001; LANGDON, 1996, 2003).

Realizei entrevistas em profundidade com 13 mulheres $^{2}$ HIV+ provenientes das classes populares urbanas e observação participante do I Encontro Paranaense de Pessoas Vivendo com HIV/Aids (I EPPVA), ocorrido na cidade de Foz do Iguaçu/PR em maio de 2005. Essas mulheres têm entre 26 e 50 anos; oito são católicas; quatro, evangélicas; e uma é umbandista. Dez se auto-referiram como heterossexuais; uma se auto-referiu como bissexual; uma, como lésbica; e uma não respondeu a essa questão. Apesar de uma mulher se auto-referir como bissexual e outra como lésbica, ambas contraíram o vírus de homens que, naépoca, eram seus parceiros. Em relação à filiação política partidária, dez afirmaram não ter; uma afirmou ser filiada ao Partido da Social Democracia Brasileira (PSDB); uma, ao Partido Social Cristão (PSC); e uma, ao Partido do Movimento Democrático Brasileiro (PMDB). Três das mulheres têm ensino médio completo; uma tem ensino médio incompleto; seis têm ensino fundamental completo; e três têm ensino fundamental incompleto. Quatro delas são casadas; três, viúvas (os maridos morreram de Aids); duas, divorciadas; e quatro, solteiras. Das quatro mulheres que disseram ser solteiras, uma delas morava com um homem havia mais de dois anos, e contraiu o HIV de um com o qual tinha morado anteriormente; e três que estavam sozinhas então, também haviam contraído o HIV de um homem com o qual tinham morado.

\footnotetext{
${ }^{2}$ Todas as mulheres que participaram desta pesquisa contraíram o HIV de seus maridos, parceiros ou namorados.
} 
$\mathrm{Na}$ análise, utilizei a abordagem antropológica da narrativa como forma de interpretação da experiência individual e coletiva, uma vez que a biografia, ao tornarse discurso narrado pelo sujeito autor e protagonista, sempre instaura um canal de renegociação e reinvenção identitária (CARVALHO, 2003). Segundo Maluf (1999), o auto-relato pode ser tomado como um locus privilegiado do encontro entre a vida íntima do indivíduo e a sua inscrição numa história social e cultural. Ao perguntar quem é esse sujeito me remeto a uma escolha teórica e metodológica e a opção de trabalhar com as narrativas das mulheres que participam do ativismo paranaense se deu pelo entendimento de que esse abriu, àquelas, possibilidades de escolha e um repertório de vivências que cada uma percorre segundo seus itinerários singulares, e cada percurso individual atrelado a essas experiências confunde-se com a história de vida, modificandoa e dando-lhe novos sentidos (MALUF, 1999). Deste modo, torna-se necessário levar em conta a experiencia singular (ligada a uma dimensão coletiva e social) e o significado dado a essa experiência por sujeitos singulares, para o entendimento dos processos de inserção política e mudança de vida ocasionados a partir da experiência de uma doença, neste caso a Aids.

0 material etnográfico aponta para uma dimensão privilegiada de análise, a noção de pessoa, a qual é constituída por três aspectos (ou momentos) diferenciados e, ao mesmo tempo, imbricados: a construção da noção de pessoa relacionada a valores de preeminência do todo, e não do indivíduo; à corporalidade; e à participação política. Esses aspectos estão articulados ao gênero, e este, por sua vez, está imbricado com a dimensão política, o que dá contornos específicos ao ativismo dessas mulheres.

Esses três aspectos encontram-se entrelaçados nas narrativas. Os limites que os separam são tênues e fazem parte de uma totalidade, ou seja, esses aspectos constroem esses sujeitos, as mulheres ativistas. As narrativas femininas mostram que a noção de pessoa diz respeito a um "sujeito em movimento", conforme definição de Maluf (1996), o qual não pode ser tomado como uma substância ou um modelo definido de pessoa: deve ser tomado como uma noção permanentemente reconstruída e redefinida.

\section{A Noção de Pessoa ao Invés de Indivíduo}

A análise da noção de pessoa, entendida aqui como uma categoria em transformação, inclui a discussão teórica sobre classes sociais e universo simbólico. A bibliografia sobre essa discussão - Heilborn (1999), Heilborn e Gouveia (1999) e Duarte (1986), por exemplo - afirma que existe uma valorização da lógica cultural moderna e individualista pelas classes médias brasileiras, enquanto as classes populares estão pautadas em valores mais englobantes, de preeminência do todo, engendrando articulações mais estreitas entre a família, o sexo e o gênero. 
0 conjunto das narrativas evidencia a importância dada ao status de casada e à família, esta compreendida aqui não apenas como um núcleo doméstico, mas como uma rede de reciprocidade. As mulheres não culpam seus maridos pela infecção do HIV, a questão do cuidado está presente como uma "obrigação de esposa". Os laços familiares, principalmente com a família consangüínea, mantém-se intensos para elas mesmo após a descoberta do HIV, constituindo muitas vezes a única referência familiar para os homens (seus maridos), como evidencia a fala de Joana, uma de minhas interlocutoras:

Quanto a minha família, eu não tive problema nenhum. Minha famíliaé maravilhosa, é dez; éa melhor família do mundo, porque quando eles descobriram minha sorologia, foram os primeiros a dar apoio. Minha mãe nunca me discriminou, nem minhas irmãs, nem meus sobrinhos. Sou amada por eles todos. Eles sempre estão aqui, deu pra você perceber. 0 , já tem três rodando aqui, e é assim direto. Eles brigam pra dormir na minha casa; minha casa é um cubículo, tem horas que eu fico até nervosa! É porque querem tudo ficar aqui com a tia. Quando eu fiquei doente, meus cunhados, minhas cunhadas foram lá para o hospital. Eu senti que a minha família sempre foi muito maravilhosa, eles brigam por mim; se alguém fala mal de mim por causa do HIV, eles brigam por isso. A minha família me deu muito apoio, minha mãe. Admiro a minha mãe muito, porque ela tinha, na época que eu descobri, 62 anos. E eu falei pra ela que eu estava: descobri, cheguei em casa e contei. Ela não me discriminou, não separou nada de mim (...)Em casa, eu cheguei e contei. Aí, eles queriam matar o meu marido, falei: "Ó, se vocês me amarem, vocês não fazem nada pra ele, porque ele não tem culpa". Porque eu acredito assim, eu falo que o Pedro não teve culpa, porque ele foi uma vítima, como eu fui e muitos serão, porque muitos passam sem saber que está com HIV. A família diz que eliminou ele. 0 Pedro morreu, eu acho que ele morreu mais de depressão, e não da AIDS em si, sabe?, porque, hoje, eu vendo amigos meus que teve várias infecções, e ele não teve isso. A mãe dele não chegava perto dele. Ele adoeceu e morreu. No hospital, com ele ficava só eu, e a mãe dele não ia lá no hospital visitar. Quando ele veio pra cá [para casa], quem vinha era a minha família. Tanto que, no dia que ele morreu, no velório dele os parentes [de Pedro] foram só quase na hora do enterro. Os parentes que tinha aqui, que passaram a noite, foi toda a minha negrada, que eu falo, a minha família. A mãe dele foi dormir, então você imagina. Então eu acho que ele morreu mais de depressão. E eu não tenho isso. A minha família, nossa!, nunca teve preconceito, me defende muito, me apóia muito. (Joana, 36 anos)

Em minha dissertação de mestrado escolhi duas entrevistas para trabalhar mais profundamente, uma delas é a narrativa de Joana, que é viúva e tem 38 anos. É negra, católica e filiada ao PSDB. Cursou até a oitava série do ensino fundamental, era zeladora e agora está aposentada. Concedeu-me duas entrevistas, ambas em sua casa, em uma 
pequena cidade no interior do Paraná. Ela mora com sua filha, de 15 anos, em uma casa modesta, e, nas duas vezes em que a encontrei, estava muito feliz, pois estava construindo mais alguns cômodos. Joana não atua em uma ONG/Aids, mas participa do Conselho de Saúde de sua cidade e está a par dos acontecimentos que envolvem a política de saúde local. Nas eleições de 2004, Joana candidatou-se a vereadora em sua cidade, e o mote de sua campanha era a prevenção do HIV. Ela acredita que um dos caminhos para a maior visibilidade das pessoas HIV+ é a entrada na política partidária. Em cada entrevista conversamos por aproximadamente duas horas e meia, e ela começou falando sobre como ficou sabendo que era HIV+, há dez anos, quando o marido, Pedro, ficou doente de Aids:

Eu era casada [...] fazia quatro anos que eu estava com meu marido. Ele morou com uma mulher em São Paulo e se separou dela pra vir embora; teve uma outra mulher e me conheceu. A gente começou a namorar e fomos morar juntos; eu estava grávida quando esta mulher morreu. Daí, um dia ele me chamou, contou pra mim [sobre seu exame HIV positivo]. A gente foi em uma lanchonete e ele contou, e eu não levei um choque porque não adiantava; naquela época já era pra eu estar [com o HIV]. Eu já tinha a minha filha - porque a minha filha eu tive solteira, ela não é filha dele. Então ele soube [que estava com HIV]. Quando soube, ele ficou uns três dias muito triste, muito abalado. [...] passando dois meses, durante esse tempo eu me preparei, eu sabia que podia ser [HIV+], e comecei a ler tudo que falava de Aids, até, inclusive eu tirei sarro, dou risada, porque tinha um dentista que eu ia e eu roubei uma revista dele porque tinha um assunto de Aids lá; e eu não sabia como falar pra a secretária pra ela me emprestar, daí eu roubei a revista. E aí me informei sobre tudo o que era a Aids. Era 97, 98, por aí; 97! Aí eu fui ao consultório, conversei com o médico e contei que a mulher [que havia morado com Pedro São Paulo] já tinha morrido. Daí o doutor me deu o pedido do teste ELIZA, e eu fiz. Isso escondido do meu marido, porque ele não aceitava, e ele já era um doente de Aids, porque ele já tinha diarréia. Aí eu peguei! Ele não aceitava ser HIV positivo, por isso é que eu fui só, falei com o médico.

Em estudo que analisa as implicações das oposições de gênero nas relações de ordem subjetiva e íntima entre casais soroprevalentes para o HIV, privilegiando a representação feminina sobre o gênero masculino, Knauth (1994) aponta que, na concepção das mulheres, os homens são mais sensíveis à dor e aos sintomas do HIV, apesar de serem mais resistentes fisicamente, pois (segundo elas) dificilmente ficam doentes; e, por não aceitarem o fato de estar doentes, são mais atingidos emocionalmente pela doença. Depois de Pedro lhe contar que era HIV+, Joana passou dois meses sem saber se era ou não, pois ele, que se recusava a falar sobre o assunto, não queria que ela fizesse o teste. Pedro estava debilitado fisicamente, por já estar doente de Aids, e não agüentou muito tempo — na opinião de Joana, porque estava deprimido. 
No período que precede a confirmação da sua sorologia positiva ao HIV, Joana estava grávida, e conta que um dia rezou a Nossa Senhora Aparecida pedindo que the tirasse o filho caso ela estivesse infectada, porque não queria que ele nascesse com Aids:

Aí eu descobri que estava grávida e me apavorei. Naquele tempo, falavam assim: "Aids mata" - e eu tinha muito medo do meu filho nascer. [...] antes disso, eu estava grávida de dois meses e meio, por aí, numa noite eu rezei. Eu sou muito devota a Nossa Senhora Aparecida; eu rezei pra Nossa Senhora um terço e pedi pra ela que se eu estivesse com Aids e meu filho fosse nascer com Aids, que ela me desse um sinal e tirasse meu filho, porque eu não queria - e eu tive um aborto. Eu tive esse aborto, no outro dia eu tive certeza [de que tinha contraído o HIV]. Aí eu fui ao médico e ele falou: "Só falo que você estava grávida porque eu senti o coração da criança bater, porque senão...". Quer dizer, não precisou fazer limpeza, curetagem, nada, ele só me deu uns remédios pra eu tomar porque tinha tido o aborto, pra não dar infecção. E aí eu fui fazer o teste. Fiz 0 exame de HIV; fui pegar, deu positivo.

Segundo Knauth (1997) e Leal e Lewgoy (1995), no entendimento dos grupos populares, o aborto, seu sucesso ou fracasso, aparece como "obra ou vontade divina", e é esse argumento que justifica, por exemplo, o fato de "um mesmo método ser eficaz para algumas mulheres, ou em uma determinada situação, e não em outras" (KNAUTH, 1997 , p. 42). No caso de Joana, o aborto foi interpretado como um sinal divino de que ela era HIV+. De acordo com Knauth, entre mulheres HIV+ a opção por fazer um aborto se dá menos em razão do HIV do que de um "balanço" de suas condições materiais de existência. No caso de Joana, o aborto não foi provocado, e sim espontâneo, ou melhor, aconteceu por "vontade de Nossa Senhora".

Para a análise das narrativas das mulheres ativistas, é relevante compreender o contexto no qual se deu a sua infecção pelo HIV. Como mencionei, elas contraíram o vírus de seus maridos ou namorados. A maior parte das que estavam casadas já mantinha a aliança havia algum tempo e algumas já tinham filhos (fossem de seus maridos ou de um outro relacionamento) antes da descoberta. Duas contraíram o HIV do namorado. Atualmente, algumas não estão mais casadas nem namoram o mesmo homem, no entanto nenhum casamento ou namoro foi rompido em conseqüência do HIV e de sua descoberta. Nas narrativas daquelas que estavam casadas já havia mais de um ano, certa "legitimidade" é atribuída a fato de o marido as terem infectado, ou seja, elas não os culpam. Essa "legitimidade" está expressa nos relatos quando, em um tempo narrativo, remetem-se ao período de suas vidas em que "não sabiam da Aids", "não tinham informações", e sentiam-se protegidas por serem casadas. Algumas narrativas apontam para o fato de terem sido "vítimas" da Aids, como se a infecção pelo HIV fosse 
uma espécie de "destino"ou "condição" de serem casadas. Também a visão que as mulheres têm dos homens legitima em geral o fato de eles as terem infectado, pois consideram a conduta sexual daqueles como "indisciplinada", naturalizando, assim, 0 fato de serem infiéis ${ }^{3}$ (HEILBORN; GOUVEIA, 1999).

Luiza $^{4}$ contraiu o vírus do HIV de seu marido. Segundo ela, casou-se contrariada, por pressão da mãe, pois estava grávida. Ela perdeu o filho e, decorridos seis meses, descobriu-se HIV+:

[...] foi assim: eu namorei com um outro cara três anos, aí a gente se separou, e um dia eu estava na Concha Acústica e conheci o César, que é o meu falecido; quando eu vi ele pela primeira vez, eu achei ele muito parecido com o meu ex-namorado, e eu comecei a paquerar ele nesse dia. $\mathrm{E}$ a gente se conheceu, tal, a gente namorou três anos, aí eu fiquei grávida e me casei com ele. Me casei contrariada, eu nunca tinha pensado em me casar; casei grávida e casei mais por pressão da minha mãe, que "Ái, se seu pai descobrir que você está grávida vai te por pra fora de casa", e não sei o quê, não sei o quê - e eu acabei me casando com ele. Na época ele... na época! Nunca trabalhou e eu também não trabalhava, mas a mãe dele trabalhava num motel, e lá fui eu trabalhar com ela nesse motel, e morar nesse motel. Eu estava grávida de três meses; seis meses depois foi a época que eu tive o bebê, que eu perdi, e seis meses depois que eu perdi o bebê, eu descobri que eu tinha Aids. Já estava na época de eu ganhar, já estava de nove meses, e um dia eu senti que ele não estava mexendo, tal, e eu tinha uma folga no motel uma vez por semana, que era numa quinta-feira, e nessa quintafeira eu sempre saía pra comprar as roupinhas do bebê e, na época, a minha irmã também estava grávida junto, e nesse dia a gente tinha andado bastante, tal. Daí, do centro eu fui pra casa dela, estava jantando, daí chegou um amigo da gente e a gente começou a falar de gravidez, né?, que a gente estava grávida praticamente juntas, e aí a gente falando de mexer, mexer bastante, "mexe, não sei o quê". Daí eu lembrei que

\footnotetext{
${ }^{3}$ Nesse sentido, o relato de Joana é revelador: "0 meu marido era muito biscateiro, daí eu descobri que ele tinha tido um caso com uma mulher em [...] [nome da cidade], e que ela queria me conhecer. Eu não a conheci, nunca quis, mas dizem que sim [que é HIV+]. Quem sabe ela já morreu. Teve três mulheres aqui [com as quais o marido relacionou-se fora do casamento] — duas já morreram, a outra foi embora —, que ele contaminou só que assim, ele me traía, mas ele me amava. Eu falo assim: verdadeiramente, foi o único homem que me amou".

${ }^{4}$ A segunda narrativa que trabalhei em profundiade em minha dissertação foi a de Luiza. Vale ressaltar que no presente artigo trago outras narrativas relevantes para as questões que aponto para revelar como ao trabalhar com trajetórias me deparei com muitas que contrastam entre si, o que permite considerar este movimento social de modo mais crítico, sem uniformizá-lo . Luiza é viúva, tem 37 anos e um filho de 9 anos, que também é HIV+. É católica "não-praticante", não é filiada a partido político e tem o primeiro grau completo. Disse nunca ter tido uma profissão, mas já trabalhou como secretária e auxiliar-geral. Nossa conversa teve duração de uma hora e meia e se deu numa sala da ONG em que atua há aproximadamente dez anos, tempo em que participou de várias atividades da instituição, assim como foi auxiliar de coordenação de projetos. Tivemos outras oportunidades de conversar, mas, durante a gravação da entrevista, ela estava bastante nervosa, preocupada em responder "certo" às perguntas, e algumas vezes me pediu para desligar o gravador.
} 
o meu bebê não tinha mexido, que eu tinha andado bastante, e, na gravidez, quando você se mexe bastante, mais o nenê mexe, e daí eu fiquei meio assustada, não falei pra ninguém, estava na casa da minha irmã. Simplesmente levantei, falei que ia embora e fui embora. Cheguei na minha casa, deitei na cama e comecei a mexer na minha barriga, mexer de tudo quanto é lado. Mexe, mexe, mexe, e o bebê nada de mexer. Chorei muito, porque eu estava sozinha, o César estava trabalhando no restaurante, entregava marmita à noite e, ah, chorei até pegar no sono, e aí, no outro dia de manhã, tive que trabalhar às seis meia da manhã, mas levantei, fui pra portaria do motel; a minha sogra trabalhava à noite e eu, de dia. Daí eu peguei e falei pra ela: "0́, então, acho que o meu bebê não mexe desde ontem". Aí ela ficou assustada e falou assim: "Como assim, não mexe, se não mexe tem que ir no médico". Daí o patrão da gente vinha pra buscar ela, e ele chegou e ela falou pra ele, e eles me levaram pro HU. Daí foi quando eu descobri que o neném estava morto já fazia 24 horas. Daí ganhei ele, mas seis meses depois eu descobri sobre o vírus. Eu não cheguei a ter o bebê, ele já estava morto.

Um ano depois de ter perdido o filho, o marido de Luiza, César, sofreu um acidente e ficou quatro meses em coma, no hospital. Quando recebeu alta e foi pra casa, necessitava de cuidados especiais, pois estava em estado vegetativo. César viveu ainda cinco anos, e ela "cuidou dele até o fim". Disse que não teve raiva do marido, pois, como era casada, considerava-se na "obrigação de cuidar":

Não, eu não fiquei com raiva dele. Não, eu gostava muito dele, sabe? Aí eu voltei — eu tinha ido no HU de manhã — ele veio almoçar e falou: "E aí? O que o povo queria?" — porque ele sabia que eu tinha ido lá, né?, e eu falei: "Almoça que depois a gente conversa". Daí ele falou pra mim... Ah, ele almoçou, a gente deitou na cama e começou a conversar, e eu falei pra ele, e aí ele levou um susto. Eu falei: "Olha, você vai ter que ir lá fazer exame, pra ver se o seu exame também é positivo"; e expliquei tudo o que o médico tinha me explicado. Aí ele voltou, fez o exame e ele também era soropositivo. E aí a gente começou a fazer o tratamento. Todo mês a gente ia lá na consulta. Até que ele sofreu esse acidente e tudo aconteceu, ficou cinco anos na cama, eu cuidando dele, a minha vida... sabe, tudo isso? Eu gostava muito dele, né? Um dos motivos era esse, apesar de tudo o que ele fez, eu gostava muito dele. E a família dele não quis saber dele, tanto que ele sofreu esse acidente, ficou quatro meses em coma, a mãe dele é que ia de vez em quando no hospital; e, depois que ele ficou no estado que ficou, que ele ficou na cama, fazia xixi, cocô, tudo na cama, e eu e a minha mãe é que cuidava dele. E ela ficou sabendo [sobre o HIV], a mãe dele, no hospital, bem depois. Ninguém sabia até 0 acidente dele, nem a minha família, eles descobriram todos nessa época do acidente dele. E a família dele não quis saber dele, então eu era casada com ele e me senti na 
obrigação de cuidar. Sei lá, eu ainda gostava dele no começo, até conhecer o Tico... Ah, eu cuidei dele, a família não quis saber.

Nesse sentido, Knauth (1994), em estudo sobre um grupo de mulheres HIV+ de Porto Alegre infectadas por seus maridos, afirma que nenhuma aliança conjugal foi rompida em razão da Aids ${ }^{5}$. As mulheres que entrevistou não os culpavam por tê-las infectado, uma vez que, em seu entendimento, eles não agiram de forma intencional, bem como não concebiam a ruptura da aliança como uma alternativa para a situação. Para essas mulheres, o papel de cuidar dos maridos era um compromisso assumido na concretização do casamento, desresponsabilizando as mulheres da família consangüínea do homem, que, até aquele momento, desempenhavam o papel de suas cuidadoras. Segundo a autora, o casamento, para os homens, parece implicar uma ruptura com sua família consangüínea; já para as mulheres, os laços mantêm-se intensos mesmo depois da aliança, o que faz que se percebam como a única referência familiar para o marido. Essa situação é muito presente nas narrativas das mulheres ativistas que são viúvas; elas cuidaram de seus maridos "até o fim", pois se sentiam responsáveis, como parte de uma "obrigação" de esposa. Uma das mulheres que se auto-referiram como solteiras, mas que contraiu o HIV de um homem com o qual viveu muito tempo, também cuidou dele "até o fim". Também parece estar com elas a "legitimidade" de revelar ou não, para a família ou outros, a sua sorologia e a do marido; são elas que definem 0 melhor momento para contar ou, ainda, que decidem tomá-las como um segredo ${ }^{6}$.

Mesmo em uma das narrativas, em que fica clara uma mudança significativa no casamento, por conta da mágoa por o marido tê-la infectado, a separação não é encarada como saída ${ }^{7}$. Segundo Knauth (1995), para as mulheres HIV+ a separação apresenta-se como uma possibilidade apenas imediatamente após o teste, quando tomam conhecimento de sua sorologia positiva, e mesmo existindo certa "pressão social" para a separação, principalmente por parte da família consangüínea, elas entendem que separar-se não resolve a situação. Nesse sentido, Alice afirmou: "Se eu largasse dele e eu sarasse, se ficasse descontaminada, você acha que eu não teria feito? Na mesma hora. [...] Não adianta eu largar dele, porque eu já estou contaminada". Em sua narrativa também aparece a "obrigação" do cuidado como algo fundamental na aliança: "Assim

\footnotetext{
${ }^{5}$ Sobre essa questão, ver, também, Martin (1997).

${ }^{6}$ Em estudo com casais sorodiscordantes para o HIV, Maksud (2005) faz o mesmo apontamento sobre a legitimidade das mulheres em revelarem o fato de serem HIV+ para a família, parentes e amigos. Knauth (1995) também afirma que as mulheres acionam um conjunto de estratégias para manter sua identidade e seu status social, e entre elas está a não-revelação da soropositividade aos consangüíneos.

7 Refiro-me a narrativa de Alice que mora numa cidade no oeste do estado do Paraná, casada há mais de dez anos.
} 
como ele me cuida, eu também vou cuidar dele pro resto da vida; enquanto nós estivermos juntos, nós vamos ficar juntos".

Ainda segundo a autora, as mulheres apresentam dois argumentos para justificar a decisão de manter o casamento. 0 primeiro diz respeito ao papel de esposa, pois tratase de um compromisso assumido na concretização da aliança: o de cuidar do marido. 0 segundo refere-se a uma série de conseqüências, enumeradas por elas, que poderiam ser provocadas pela ruptura da aliança, relacionadas à vulnerabilidade masculina, ou seja, as mulheres têm medo do que possa acontecer com seus maridos, pois, na concepção delas, eles sempre precisam de alguém que "cuide" deles.

De acordo com Knauth (1994), as mulheres HIV+ consideram os homens seres "naturalmente livres" - em sua concepção, eles dispõem de maior liberdade porque estão associados ao espaço público e porque necessitam de liberdade para viver. Segundo essas mulheres, fazem parte da "natureza masculina" o uso de drogas e álcool (mesmo que elas não aceitem isso), bem como as relações extraconjugais, uma vez que "eles não conseguem se conter sexualmente".

A minha interlocutora, Alice, que não desculpa o marido por tê-la infectado, considerava, no passado, seu casamento "perfeito"; depois que soube ser HIV+, ela ficou "muito magoada" e acha "que nunca vai cicatrizar esta ferida". Não mantém relações sexuais com o marido desde que descobriu que é HIV+. Hoje, "Não que nós brigamos [...], nós vivemos na mesma casa, vivemos assim, não é mais assim como era [...] nós vivemos mais assim como amigo dentro da casa". Os dois não conversam sobre a questão do HIV e ela não sabe como o marido se infectou, pois ele "é muito quieto, se eu quero saber uma coisa tenho que insistir muito". Em sua opinião, nada justifica o "desrespeito" que ele teve com ela. No entanto, quando especulou sobre como o marido teria contraído o HIV, disse: "Ele vivia indo em churrasco, nessas coisas assim, e um dia ele tava meio, né?, tomou umas cervejas demais, sabe como é que é homem, né?". Além disso, declarou: "No começo eu pensava assim: se eu chegasse a descobrir de quem ele pegou, eu era capaz de ir atrás e matar". Ela não o desculpa por tê-la infectado, e o fato de serem HIV+ é mantido em segredo para a família e os amigos. Mesmo tendo a reclamar do comportamento dos maridos, as mulheres ativistas lhes atribuem apenas uma parcela da responsabilidade pela infecção, já que as relações extraconjugais e o uso de drogas e bebidas são intrínsecos à condição masculina. Knauth (1995) demonstra que, na perspectiva feminina, a culpa é sempre dos outros, ou das "más companhias", ou das "mulheres da rua".

$\mathrm{Na}$ ocasião de nossa conversa, Joana contou que um médico sugeriu uma laqueadura, mas ela não aceitou, porque, se a fizesse, ia se sentir "espoliada" de uma 
parte de si: "fazer uma laqueadura, acho que vai tirar uma parte que é do sexo [...] como se fosse inútil, né?, porque já tem a dificuldade de um parceiro. De repente eu faço uma laqueadura, daí eu sei que eu nunca vou ter filho [...]". A maternidade é um valor que constitui a noção de pessoa das mulheres ativistas, e a dimensão sexual, apenas, não daria conta dessa identidade, pois esta está relacionada à maternidade e ao cuidado dos filhos.

No momento de nosso diálogo, Joana demonstrava um sentimento ambíguo em relação a ser mãe novamente, uma vez que já tinha uma "filha grande" e ter outro filho tiraria sua "liberdade" de fazer o que quisesse, mas a laqueadura, segundo ela, representaria um bloqueio, pois tinha "medo de perder alguma coisa". Na última vez em que a vi, em maio de 2005, durante o I Encontro Paranaense de Pessoas Vivendo com Aids (I EPPVA), ela estava grávida. Quando the perguntei se em algum momento tinha pensado em fazer um aborto, ela respondeu que não. Inclusive, em depoimento na plenária final desse evento, disse que "É um presente ser mãe novamente e falar para a sociedade que estou grávida", e que a "Aids doeu”, pois havia pensado que, por conta da doença, não deveria mais ser mãe, por medo de morrer e deixar os filhos.

Entre as mulheres, a preocupação com quem deixar os filhos é mais presente do que a de interromper as funções reprodutivas, o que muitas vezes causa um conflito com os serviços de saúde e com os médicos, que em geral consideram essas mulheres irresponsáveis, uma vez que, no imaginário médico, o que é ressaltado é o risco da transmissão vertical, apesar de muitas pesquisas ${ }^{8}$ apontarem que 0 tratamento com AZT durante a gravidez, a sua aplicação por via injetável durante o parto e o cuidado da mulher HIV+ em não amamentar o filho, e/ou de pasteurizar" o leite, diminuem significativamente esse risco. 0 Movimento Nacional de Mulheres que Vivem com HIV, as Cidadãs PositHIVas ${ }^{10}$, publicou um material no qual há um capítulo intitulado "Relatos sobre violência cometida contra os direitos reprodutivos das mulheres com HIV/Aids" (BRITO; PIZÃO; SOUTO, 2002), que reúne uma série de depoimentos de mulheres HIV+ e retrata as dificuldades do SUS de lidar com elas quando grávidas, as prescrições médicas nesses casos e as relações de poder existentes entre médicos e pacientes.

\footnotetext{
${ }^{8}$ Entre outros estudos sobre os riscos da transmissão vertical, ver Grinsztejn (2002).

${ }^{9}$ A pasteurização é o processo pelo qual passa o leite materno para eliminar o HIV. Dessa forma, torna-se possivel uma mãe HIV+ amamentar seu filho.

${ }^{10} 0$ Movimento Nacional de Cidadãs PositHIVas (MNCP), ou Cidadãs PositHIVas, foi criado em 2000 por mulheres HIV+ com o objetivo de lutar pela construção de políticas públicas de saúde voltadas para as especificidades das mulheres HIV+, entre as quais a necessidade de vê-las como um "ser inteiro", ou seja, para além da reprodução e da transmissão vertical, contemplando questões como o uso de medicamentos anti-retrovirais na menopausa e as cirurgias corretivas em decorrência da lipodistrofia (BRITO; PISÃO; SOUTO, 2002).
} 
A partir de uma pesquisa realizada nas cidades de São Paulo e Porto Alegre, com 60 mulheres HIV+, em sua maioria provenientes das classes populares, Knauth et al. (2002), discutindo a cultura médica e as decisões reprodutivas entre mulheres HIV+, procuram evidenciar os fatores que determinam as escolhas dessas gestantes, principalmente no que diz respeito à escolha do tipo de parto e à decisão pela esterilização. Segundo as autoras, a condição de portadora do HIV faz que, entre essas mulheres, o parto seja percebido como uma prescrição médica ${ }^{11}$. Se, em geral, há a suposição de que as decisões reprodutivas se dão no nível do relacionamento dos parceiros, assim como no nível intrapessoal, no caso de mulheres HIV+ o contexto institucional parece assumir o maior peso.

Tal como sugerem Knauth et al. (2002), para as gestantes portadoras do HIV+ as decisões reprodutivas são um problema médico. Embora elas tenham desejos e experiências relacionados a essas decisões, esses encontram-se submetidos às prescrições médicas e às condutas dos serviços de saúde aos quais estão vinculadas. Segundo as autoras, para essas mulheres a "escolha" pelo parto cesáreo encontra-se vinculada à interpretação do discurso médico. A cesariana é entendida enquanto uma prescrição médica, e, assim, o desejo de ter parto normal, por exemplo, é colocado em segundo plano em função da prescrição. No entanto, apesar de o parto cesáreo ser percebido como prescrição médica, nem sempre ele acontece, pois "é o tipo de serviço de saúde ao qual a gestante encontra-se vinculada que determinará o desfecho final, isto é, a maior ou menor probabilidade de realização da própria indicação" (KNAUTH et al., 2002, p. 46).

É recorrente, nas narrativas das mulheres ativistas, a discussão sobre o desejo ou a possibilidade de ter filhos. Em muitas delas, a laqueadura, medida de contracepção considerada como a mais "adequada" nos serviços de saúde para mulheres HIV+, aparece como tendo sido a melhor escolha, mas, em outras, ela é recusada, caso de Joana, que, se a fizesse se sentiria "espoliada de uma parte que é do sexo".

Rohden (2002), discutindo os significados e os valores associados à possibilidade de um portador do HIV reproduzir, afirma que a reprodução, em todos os seus momentos (geração, gravidez e nascimento), está associada à idéia de transmissão e continuação da vida. Inúmeros valores positivos são associados à fertilidade, à capacidade de gerar uma nova vida e, em especial, à maternidade. Em nossa sociedade, marcada pelos valores judaico-cristãos, a figura da mãe assume caráter de santidade, de respeito, de grande valor. A autora afirma que, historicamente, todas as tentativas de controle da

\footnotetext{
${ }^{11}$ Nos serviços de saúde, o tipo de parto indicado para gestantes HIV+ é o cesáreo, uma vez que, segundo a biomedicina, ele diminui os riscos da transmissão vertical.
} 
fertilidade e da natalidade foram combatidas, vistas como imorais e condenadas ${ }^{12}$, e, como a sociedade ocidental está pautada em relações de gênero que têm nos papéis de mãe e esposa um "pilar fundamental" de seus valores, as interferências na função reprodutiva são percebidas como ameaçadoras.

Segundo DaMatta (1997b), a noção de indivíduo autocontido e como unidade isolada foi largamente desenvolvida no Ocidente, enquanto nas sociedades hierarquizantes, tradicionais e holistas a noção de pessoa é dominante. Ambas as noções estão presentes em todas as sociedades, o que aponta para a existência de uma relação dialética entre elas. No Brasil, a distinção entre indivíduo e pessoa pode ser tomada, segundo o autor, como duas formas possíveis de conceber e agir no universo social, configurando-se assim um perfil relacional da sociedade brasileira.

Vale ressaltar que autores que fizeram estudos antropológicos sobre as classes médias brasileiras (VELHO, 1981; MALUF, 2001, 2002) entendem que, mesmo nesses grupos, a incorporação de uma ideologia individualista não se dá sem contradições, e sim dialogicamente, com aspectos próprios a configurações culturais mais ligadas a uma cultura holista ou hierárquica; segundo Monteiro (2002a), o mesmo acontece nas classes populares. Nas sociedades modernas, entre os grupos sociais coexistem estilos de vida variados e diferentes visões de mundo. Embora os diversos segmentos sociais estejam expostos à lógica da modernidade e vivam no mesmo espaço urbano, a incorporação e a reprodução dos valores da modernidade se dão de forma diferenciada entre eles. Nesse sentido, as classes populares têm acesso mais limitado às condições e aos valores da modernidade em comparação às classes médias, no entanto estão sujeitas a mudanças em termos de identidade social e de suas práticas (MONTEIRO, 2002b). Segundo Dumont (1993), não existe apenas um individualismo; este toma formas diferenciadas segundo contextos sociais, políticos e históricos específicos, e, assim, a dinâmica de empréstimos entre a ideologia moderna individualista e culturas holistas ou hierárquicas foi pensada pelo autor como própria da forma como o individualismo se difunde.

0 entendimento das mulheres ativistas, de que são parte do movimento político de HIV/Aids paranaense, possibilita que a experiência de gênero seja articulada à dimensão política, mudando a maneira de experienciar papéis como dona-de-casa, esposa e mãe, os quais, por sua vez, imprimem os contornos e as fronteiras simbólicas em relação aos "outros" do movimento ativista: homossexuais, travestis e prostitutas. Os valores relacionados à importância da família e a hierarquia de gênero continuam

\footnotetext{
${ }^{12} \mathrm{~A}$ autora refere-se tanto a práticas abortivas como ao uso do preservativo e de outros modos de contracepção que se disseminaram no decorrer do século XX.
} 
presentes, mas, se articulam a outros mais "modernos" ou "individualistas", como revelam quando afirmam terem adquirido maior autonomia em casa e nas suas decisões:

Antes (da entrada no movimento) eu achava que tinha que lavar, passar, cozinhar (...) Tem que ser mais ativa, participar dos conselhos, participar do que está acontecendo no colégio dos filhos, do que tá acontecendo com os filhos, não é só assim, aquela visão que a gente tem que trabalhar de empregada doméstica, chegar em casa, lavar, passar, cozinhar e não saber o que acontece ao redor, hoje penso totalmente diferente, penso diferente, assim, que não é só lavar, passar, cozinhar e deitar na cama, é diferente...que a mulher...ela assim, olha assim se falar "tô com dor de cabeça", o marido vai procurar outra fora de casa...tem que saber e dizer: "olha, eu tô com dor de cabeça, eu lavei, passei e cozinhei hoje e não vou deitar na cama, não vou fazer amor"...tem que ser mais ativa (...). ${ }^{13}$

\section{Corporalidade}

Seeger, DaMatta e Castro (1987) buscaram compreender as cosmologias ameríndias a partir dos seus próprios termos (das cosmologias ameríndias), e afirmam que elas apontam para a importância de pensar a pessoa e a corporalidade como elementos centrais da experiência vivida socialmente, pois a "produção física de indivíduos se insere em um contexto voltado para a produção social de pessoas" (SEEGER; DAMATTA; CASTRO, 1987, p. 13). Apesar de contextos etnográficos diferentes, um paralelo pode ser traçado com o segundo aspecto da articulação da noção de pessoa com a de corporalidade, uma vez que este está ligado ao desencadeamento de um "processo de aprendizado e educação dos sentidos e da experiência corporal" (VALLE, 2003, p.10).

Os sujeitos, pela inserção no movimento político de HIV/Aids, aprendem a "ser HIV+" também pela adesão ao tratamento anti-retroviral e pelos exames ${ }^{14}$ de controle, pois torna-se necessário manter uma "vida regrada" em relação aos horários de tomar remédios e se alimentar.

\footnotetext{
${ }^{13}$ Soninha tem 37 anos e mora numa cidade no centro-oeste do interior do Paraná, tem o primeiro grau completo, é católica, dona de casa, e na época de nossa conversa atuava em uma $0 \mathrm{NG} / \mathrm{Aids}$ de sua cidade. Ela afirmou que "legalmente" é solteira, mas que morava com uma homem HIV- na ocasião, contraiu o HIV de seu ex-marido que era caminhoneiro.

${ }^{14}$ Os principais exames de acompanhamento para os tratamentos são os de CD 4 e CD8, que "medem" a quantidade de leucócitos no sangue, e o de carga viral, que mede a quantidade de vírus. Também são necessários outros exames, como o hemograma, para o controle da anemia, pois alguns medicamentos (caso do AZT) podem causá-la.
} 
As narrativas das mulheres ativistas revelam a preocupação em aderir ao tratamento e ter melhor "qualidade de vida", no sentido de dormir bem, comer bem. Em relação à alimentação, elas estão interessadas em saber quais alimentos, ervas e chás são bons para o sistema imunológico, para combater/evitar a anemia, etc. Os filhos são uma preocupação presente, uma vez que o teste anti-HIV, segundo elas, representou, num primeiro momento, "um atestado de morte", e com quem deixar os filhos tornou-se uma questão central em suas vidas. Essa preocupação também existe em relação aos filhos que vão nascer e aos cuidados que deverão ser administrados para a criança "negativar"15.

0 tratamento anti-retroviral causa efeitos colaterais sérios e desagradáveis, e a lipodistrofia ${ }^{16}$ é o mais apontado nas narrativas: as mulheres lamentam a transformação do corpo, a perda das formas femininas; relembram como eram "gostosonas" ou que tinham "tudo no lugar". Há preocupação com a sexualidade, e as que estavam sozinhas colocavam a dificuldade de arranjar um namorado ou parceiro, a causa indo desde 0 preconceito por serem "positivas" até o fato de estarem "feias".

Ainda com relação ao aspecto da noção de pessoa articulado ao da corporalidade, as narativas apontam para a legitimação de um discurso e de uma prática ${ }^{17}$, ou nas palavras de uma de minhas interlocutoras, é pelo fato de "sentir na pele" o que é ter 0 HIV e as transformações corporais que os anti-retrovirais acarretam é que as pessoas HIV+ tem maior propriedade, por exemplo, para realizar trabalhos de prevenção ao HIV/Aids e assistência às pessoas vivendo com HIV/Aids, ou então, questionar a conduta médica quanto às receitas dos anti-retrovirais.

\section{ParticipaÇÃo}

Em relação ao aspecto da articulação da noção de pessoa à de participação política no movimento paranaense de HIV/Aids das mulheres ativistas, durante as

\footnotetext{
${ }^{15}$ Todas as crianças nascidas de mulheres HIV+ também são HIV+, pelo menos temporariamente, pois, caso seja feito o teste anti-HIV nelas, esse detectará a presença dos anticorpos da mãe presentes no sangue, e não o vírus. Os anticorpos maternos podem permanecer na corrente sangüínea da criança por até dezoito meses. Após esse prazo, se a criança não estiver infectada, passará a produzir seus próprios anticorpos e, dessa forma, passará de sorologicamente positiva para negativa, daí se diz que "negativou".

${ }^{16} \mathrm{~A}$ lipodistrofia é um dos efeitos colaterais dos medicamentos anti-retrovirais que atualmente são usados para o tratamento do HIV/aids. Ela é caracterizada pela redistribuição da gordura corporal devido a perda da gordura periférica, ao acúmulo de gordura central e a um catabolismo exacerbado e cronico que acabam por diminuir 0 índice de massa corpórea. (AÇÃO ANTI AIDS, 2004 ).

${ }^{17} \mathrm{~A}$ pesquisa de Valle (2002) no Grupo pela Vidda/RJ (valorização, integração e dignidade do doente de Aids), mostra como há tensões que permeiam as relações nesta instituição, dentre elas, está a do "status sorológico", no qual as pessoas HIV+ consideram-se emocionalmente mais envolvidas com a causa do que as HIV-, com maior legitimidade defendida para as primeiras.
} 
entrevistas e encontros com elas, e também em suas narrativas, constatei que sua idéia de participação política não está ligada apenas à de participação política nos moldes da teoria política moderna, como a participação em sindicatos, em partidos políticos e em espaços legislativos e executivos ${ }^{18}$. Falas do tipo "Participação é algo que vem de dentro", "Participação é aprender para passar para os outros", por exemplo, revelam outros elementos da sua noção de participação política que não estão em um domínio puramente racional e normativo da noção de participação política clássica, pois a cultura política dominante no Ocidente se caracteriza como "racionalista", "universalista" e "individualista" (MOUFFE apud ALVAREZ; DAGNINO; ESCOBAR, 2000b, p. 26).

A noção êmica de participação política dessas mulheres implica a importância de conhecer-se a partir da obtenção de informações sobre o HIV/Aids, quer sejam relacionadas à prevenção, quer sejam relacionadas ao tratamento antiretroviral ou outras. A importância da informação para aprender mais sobre a doença estrutura, igualmente, a atuação das mulheres ativistas; nesta deve haver a preocupação e a responsabilidade de "passar as informações para frente", "passar para outras pessoas", "para outras mulheres" informações sobre como colocar a camisinha, modos e meios de transmissão do HIV, como viver melhor com a medicação, que tipo de medicação é a mais indicada para cada pessoa. A noção de participação política e de política das mulheres ativistas é relacional, uma vez que idéias como "aprender com o outro", "passar para o outro" e "ser útil" fundamentam essa noção de participação e essa atuação. Além disso, esta noção de participação revela que aspectos do sofrimento podem ser compartilhados e devem servir de modelo para a "experiência" de outras pessoas (RODRIGUES; CAROSO, 1998). Para Duarte (apud RODRIGUES; CAROSO, 1998, p. 142), a idéia de gravidade da doença torna-se fundamental por mediar o plano "intrapessoal" do sofrimento e o plano da "experiência" vivenciada socialmente.

É importante destacar que uma das preocupações da antropologia, conforme afirmam Kuschnir e Carneiro (1999), é ampliar o conceito de atividade política para

\footnotetext{
${ }^{18}$ Não estou sugerindo que espaços de participação "formais", tais como em conselhos de saúde, partidos políticos e outros, não sejam importantes para o movimento de HIV/Aids paranaense ou nacional, ao contrário, a política de comunicação do movimento baseia-se no incentivo para que a pessoa soropositiva atue como um (a) protagonista político (a). Estou mostrando como existem outros elementos que atuam na motivação para a participação como a idéia de "ser útil" e "ajudar os outros".
} 
além das fronteiras de atuação do Estado ${ }^{19}$. Segundo Goldman (2001, p. 58), a antropologia se desenvolveu "buscando estudar 'outras sociedades' de um ponto de vista a elas imanente" e quando "se volta para a "sociedade do observador"" (no caso da análise de uma sociedade da qual o antropólogo faz parte), parece ter dificuldade em manter o olhar descentralizado que sempre a caracterizou; e acredita que uma possibilidade para "a antropologia das sociedades complexas" (como a nossa) "émanter o foco tradicional da disciplina nas instituições centrais da sociedade estudada, e buscar, através de uma espécie de 'desvio etnográfico', um ponto de vista descentrado". No estudo da política,

[...] tratar-se-ia de encarar as representações nativas sobre os processos políticos dominantes como verdadeiras teorias políticas, produzidas por observadores suficientemente deslocados em relação ao objeto para que possam produzir visões realmente alternativas, e de usar tais representações e teorias como guias para a análise antropológica (GOLDMAN, 2001, p. 58-59).

\section{CONCLUSÃO}

Valle (2003) e Guimarães (2001) enfatizam que fatores como classe, gênero e orientação sexual devem ser levados em consideração para se compreender a construção do saber sobre a epidemia de HIV/Aids. Segundo Guimarães (2001), as diferenças de classe e de gênero, por exemplo, implicaram formas específicas de incorporação dos saberes e das práticas biomédicas, caso das mulheres, que durante muito tempo não foram consideradas como estando em risco em relação ao $\mathrm{HIV}^{-}$e muitas ainda hoje que não se percebem em risco. Essa questão está presente nos diagnósticos médicos tardios em mulheres consideradas como de "baixo risco" para a infecção, ou seja, mulheres heterossexuais e com parceiros fixos. Ela também está presente na fala das mulheres ativistas, que antes de se tornarem HIV+ sabiam o que era o HIV e como era

\footnotetext{
${ }^{19}$ Essa preocupação com a política surge principalmente por meio dos estudos nas sociedades africanas (EVANSPRITCHARD, 2002; CLASTRES, 2003, 2004), nas quais os antropólogos, através de pesquisas etnográficas, constataram a importância de rediscutir o papel do Estado colonial e as repercussões desse modo de dominação na cultura e na organização social dos grupos locais. As relações de parentesco, de etnia e de religião são repensadas, revelando que constituem dimensões fundamentais de atualização da vida política. Por exemplo, no seu estudo sobre os Nuer, Evans-Pritchard desloca a discussão sobre a ausência de um Estado centralizado, evidenciando que o sistema de parentesco era a chave explicativa para a constituição da vida política nuer. Dessa forma, a definição de organização política dessa sociedade não se dava em uma instituição central, e sim pela existência de um "relacionamento estrutural" de antagonismos persistentes e equilibrados, expresso em guerras com povos vizinhos, mas próximos culturalmente. Segundo Kuschnir e Carneiro (1999, p. 237), "0 entendimento da estrutura política Nuer dependia da compreensão do princípio segmentário de organização dos diversos grupos e do permanente conflito entre os valores rivais dentro de um mesmo território".
} 
transmitido, mas se sentiam muito distantes do risco da infecção. A Aids existia, mas as "informações" construídas social e culturalmente, veiculadas na mídia e aceitas como verdadeiras e confiáveis, colocavam-na como uma doença do "outro", ligando-a a "grupos de risco", a "quem é que pega Aids" ou à imagem de pessoas muito magras em hospitais. Elas consideravam-se protegidas por suas relações heterossexuais e monogâmicas, por serem mães e por estarem casadas havia anos. 0 fato de terem contraído o HIV de seus maridos coloca em jogo um contraste entre conhecimento e emoção. Assim, sentimentos como "confiança", "amor" e "paixão" estão presentes quando, em um tempo narrativo, as mulheres remetem-se ao porquê de não terem se prevenido ou de não terem se percebido em risco.

Os três aspectos da noção de pessoa, discutidos anteriormente, que surgem nas narrativas das mulheres ativistas, estão relacionados à (re)elaboração da idéia de pessoa e do significado da doença depois da atuação no movimento político de HIV/Aids. A inserção no movimento político de HIV/Aids pode ser considerado um discurso capaz de criar um contexto social que dá significado à doença e oferece estratégias para controlála, fazendo parte da sua terapêutica; por sua vez, esse movimento instaura uma sociabilidade, a qual é capaz de dar um sentido político à doença.

0 material etnográfico mostra aspectos comuns àqueles descritos por uma vasta bibliografia sobre o caráter holista/tradicional do universo cultural das classes populares brasileiras. Quando abordam o contexto em que se deu sua infecção pelo HIV (através dos maridos), revela-se que a sexualidade não se constitui um domínio único de significação, e, nesse sentido, sexo e prazer estão englobados por uma moralidade mais abrangente, que articula estreitamente valores relativos à família, ao gênero e à reciprocidade, em contraposição ao tipo ideal delineado cultural e historicamente para a sexualidade moderna como um domínio portador de sentido em si mesmo. Essas mulheres, ao produzirem alteridade dentro do movimento político de HIV/Aids do Paraná, acionam suas identidades de mães e esposas. No entanto, concomitantemente, despontam nas narrativas menções a maior autonomia, a maior liberdade individual e a diferentes maneiras de viver o cotidiano do lar depois da infecção pelo HIV e da entrada no movimento. Nelas também estão presentes as referências aos direitos humanos, sexuais e das pessoas HIV+, menções a formas jurídicas de resolução de problemas e a idéia de que somos todos iguais - referências que podem ser consideradas o valor central do ideário moderno e individualista.

No entanto, para pensar esses sujeitos - as mulberes ativistas - vale ressaltar que a interpenetração de lógicas culturais é reveladora do caráter dinâmico, plural e gerador de arranjos variados, principalmente no espaço urbano. Dessa forma, a noção 
de predomínio não exclui nem impossibilita a convivência de lógicas diversas, uma vez que, nas sociedades modernas, coexistem, entre os grupos sociais, estilos de vida variados e visões de mundo diferentes. Essa constatação é relevante neste trabalho, uma vez que, apesar do predomínio de um ideário holista/tradicional, as narrativas apresentam combinações e híbridos entre esse perfil e um ideário mais moderno.

Esses fatores imprimem uma especificidade à maneira pela qual uma nova concepção de indivíduo, nesse caso, uma nova concepção de mulher, pode ser percebida no ativismo: 0 sujeito que as narrativas das mulheres ativistas refletem é a síntese de um duplo movimento, de negação e de diálogo, com a concepção de indivíduo dominante na sociedade contemporânea.

No que diz respeito à inserção no movimento político de HIV/Aids do Paraná ser constituinte de uma terapêtica, no sentido de engendrar um "aprendizado de ser soropositivo", essa terapêutica não diz respeito somente a mudanças individuais relacionadas à própria saúde, mas articula-se a um "aprendizado" que é político e implica uma reflexão que é coletiva. No caso das mulheres, essa relação entre a motivação pessoal e a participação política é importante, pois a trajetória de muitas mulheres ativistas evidencia que é a partir de uma motivação pessoal, de um projeto de controle da doença, que se descortina um projeto político para as mulheres, com atuações em partidos políticos, em alianças políticas municipais e outros. Esta reflexão é relevante quando, a partir de uma perspectiva sociológica, apontamos a subordinação das mulheres em uma sociedade que se estrutura a partir de um referencial masculino e da importância histórica pautada na esfera pública, enquanto a mulher era destinada à esfera privada.

\section{REFERÊNCIAS}

ADAM, P.; HERZLICH, C. Sociologia da doença e da medicina. Bauru: Edusc, 2001.

BOLETIM INTERNACIONAL SOBRE PREVENÇ̃̃̃O E ASSISTÊNCIA À AIDS, Ação Anti AIDS. Rio de Janeiro: ABIA, n. 51, dez. 2004. 14 p.

ALVAREZ, S.; DAGNINO, E; ESCOBAR,A. Prefácio e agradecimento da edição original em inglês. In: (Org.). Cultura e politica nos movimentos sociais latino-americanos: novas leituras. Belo Horizonte: Ed. da UFMG, 2000.

AUGÉ, M. Ordre biologique, ordre social: la maladie, forme élémentaire de l'événement. In: AUGÉ, M.; HERZLICH, C. (Dir.). Le sens du mal: anthropologie, histoire, sociologie de la maladie. Paris: Éditions des Archives Contemporaines, 1991. 
AUGÉ, M; HERZLICH, C. Introduction. In: (Dir.). Le sens du mal: Anthropologie, histoire, sociologie de la maladie. Paris: Éditions des Archives Contemporaines, 1991.

BRITO, N.; PIZÃO, J.; SOUTO, K. (Org.) Cidadãs PositHIVas. Brasília: Ministério da Saúde, 2002.

CLASTRES, P. A sociedade contra o Estado. São Paulo: Cosac \& Naify, 2003.

CLASTRES, P.Arqueologia da violência. São Paulo: Cosac \& Naify, 2004.

DAMATTA, R. Carnavais, malandros e heróis: para uma sociologia do dilema brasileiro. Rio de Janeiro: Rocco, 1997.

DUARTE, L. F. D. Da vida nervosa das classes trabalhadoras. Rio de Janeiro: Jorge Zahar, 1986.

DUMONT, L. O individualismo: uma perspectiva antropológica da ideologia moderna. Rio de Janeiro: Rocco, 1993.

EVANS-PRITCHARD, E. E. Os Nuer: uma descrição do modo de subsistência e das instituições políticas de um povo nilota. 2. ed. São Paulo: Perspectiva, 2002.

GOLDMAN, M. Segmentaridades e movimentos negros nas eleições de Ilhéus. Mana, Rio de Janeiro, v. 7, n. 2, p. 57-93, out. 2001.

GRINSZTEJN, B. Prevenção da transmissão vertical. In: MAKSUD, I. et al. (Org.). Conjugalidade e AIDS: a questão da sorodiscordância e os serviços de saúde. Rio de Janeiro: Abia, 2002.

GUIMARÃES, C. D. AIDS no feminino: por que a cada dia mais mulheres contraem AIDS no Brasil? Rio de Janeiro: Ed. da UFRJ, 2001.

HEILBORN, M. L. Construção de si, gênero e sexualidade. In: (0rg). Sexualidade: 0 olhar das ciências sociais. Rio de Janeiro: Jorge Zahar, 1999.

HEILBORN, M. L.; GOUVEIA, P. F. "Marido é tudo igual": mulheres populares e sexualidade no contexto da AIDS. In: BARBOSA, M. R.; PARKER, R. (Org.). Sexualidades pelo avesso. Rio de Janeiro: Ed. 34,1999.

JEOLÁS, L. S. O jovem e o imaginário da AIDS: o bricoleur de suas práticas e representações. 1999. Tese (Doutorado em Antropologia Social) - Pontifícia Universidade Católica de São Paulo, São Paulo. JEOLÁS, 1999.

KNAUTH, D. Um problema de familia: a percepção da AIDS entre mulheres soropositivas. Comunicação apresentada na REUNIÃO BRASILEIRA DE ANTROPOLOGIA, 19., 1994, Niterói. [mimeo]

KNAUTH, D. Evitando a morte masculina: a perspectiva das mulheres dos homens portadores do vírus da AIDS. In: ENCONTRO ANUAL DA ANPOCS, 19., 1995, Caxambu. Comunicação... Caxambu, 1995. [mimeo]. 
KNAUTH, D. Uma doença dos outros: a construção da identidade entre mulheres portadoras do vírus da AIDS. In: REUNIÃO BRASILEIRA DE ANTROPOLOGIA, 20., 1996, Salvador. Comunicação... Salvador, 1996. [mimeo]

KNAUTH, D. Maternidade sobre o signo da AIDS: um estudo sobre mulheres infectadas. In: COSTA, A. de 0. (Org.). Direitos tardios: saúde, sexualidade e reprodução na América Latina. São Paulo: Ed. 34, 1997.

KNAUTH, D. Morte masculina: homens portadores do vírus da AIDS sob a perspectiva feminina. In: DUARTE, L. F. D.; LEAL, O. F. (Org.). Doença, sofrimento, perturbação: perspectivas etnográficas. Rio de Janeiro: Fiocruz, 1998.

KNAUTH, D. Comentários ao Seminário a Sorodiscordância. In: MAKSUD, I. et al. (Org.). Conjugalidade e AIDS: a questão da sorodiscordância e os serviços de saúde. Rio de Janeiro: Abia, 2002.

KNAUTH, D. R. et al. Cultura médica e decisões reprodutivas entre mulheres infectadas pelo vírus da AIDS. Interface - Comunicação, Saúde, Educação, v. 6, n. 11, p. 39-54, ago. 2002.

KUSCHNIR, K.; CARNEIRO, L. P. As dimensões subjetivas da política: cultura política e antropologia da política. Estudos Históricos, Rio de Janeiro, n. 24, p. 227-247, 1999.

LANGDON, E. J. A doença como experiência: a construção da doença e seu desafio para a prática médica. Florianópolis: PPGAS-CFH/UFSC, 1996. (Antropologia em Primeira Mão).

LANGDON, E. J. Cultura e processos de saúde e doença. In: SEMINÁRIO SOBRE CULTURA, SAÚDE E DOENÇA, 2003, Londrina. Anais... Londrina, 2003. p. 91-107.

LEAL, O. F; LEWGOY, B. Pessoa, aborto e contracepção. In: LEAL, O. F. (Org.). Corpo e significado: ensaios de antropologia social. Porto Alegre: Ed. da UFRGS, 1995.

MACHADO, L. M. V. Atores sociais: movimentos urbanos, continuidade e gênero. São Paulo: Annablume, 1995.

MALUF, S. W. Les enfants du Verseau au pays des terreiros: les cultures thérapeutiques et spirituelles alternatives au sud du Brésil. 1996. Thèse (Doctorat en Anthropologie Sociale et Ethnologie) - École des Hautes Etudes en Sciences Sociales, Paris.

MALUF, S. W. Antropologia, narrativas e a busca de sentido. Horizontes Antropológicos, Porto Alegre, v. 5, n. 12, p. 69-82, 1999.

MALUF, S. W. Criação de si e reinvenção do mundo: pessoa e cosmologia nas novas culturas espirituais no sul do Brasil. In: REUNIÃO DE ANTROPOLOGIA DO MERCOSUL: Antropologia da pessoa: processos de individualização na cultura contemporânea, 4, 2001, Curitiba. Comunicação... Curitiba, 2001. [mimeo].

MALUF, S. W. Pessoa e corporalidade: cruzamentos entre dois campos antropológicos. In: REUNIÃO BRASILEIRA DE ANTROPOLOGIA: Pessoa e corporalidade, 23., 2002, Gramado. Comunicação... Gramado, 2002. [mimeo]. 
MAKSUD, I. Puro x impuro, sagrado x profano: práticas sexuais e situações liminares entre casais com sorologias distintas para o HIV/AIDS. In: REUNIÓN DE ANTROPOLOGÍA DEL MERCOSUR: Identidad, Fragmentación y Diversidad, 6., 2005, Montevidéo. Programa y resúmenes... Montevidéo: Departamento de Antropología Social-Faculdad de la República, 2005. p. 249.

MARTIN, D. Mulheres e AIDS: uma abordagem antropológica. Revista USP, São Paulo, n. 33, p. 88-100, mar./maio, 1997.

MONTERO, P. Magia e pensamento mágico. São Paulo: Ática, 1986.

MONTEIRO, S. Comentários. In: MAKSUD, I. et al. (Org.). Conjugalidade e AIDS: a questão da sorodiscordânciae os serviços de saúde. Rio de Janeiro: Abia, 2002a. (Comentários ao Seminário "Prevenção e Reprodução no Contexto do HIV/AIDS") Monteiro (2002a).

MONTEIRO, S. Gênero, saúde e proteção entre jovens: um perfil tradicional. In: BARBOSA, R. M. et al. Interfaces: gênero, sexualidade e saúde reprodutiva. Campinas: Unicamp, 2002b.

ROHDEN, E. Comentários. In: MAKSUD, I. et al. (Org.). Conjugalidade e AIDS: a questão da sorodiscordância e os serviços de saúde. Rio de Janeiro: Abia, 2002. (Comentários ao Seminário "Prevenção e Reprodução no Contexto do HIV/AIDS")

RODRIGUES, N; CAROSO, C. A. Idéia de "sofrimento" e representação cultural da doença na construção da pessoa. In:DUARTE, L. F. D.; LEAL, O. F. (Org.). Doença, sofrimento, perturbação: perspectivas etnográficas. Rio de Janeiro: Fiocruz, 1998.

SEEGER, A.; DAMATTA, R.; CASTRO, E. V. A construção da pessoa nas sociedades indígenas brasileiras. In: OLIVEIRA FILHO, J. P. de. (Org.). Sociedades indigenas e indigenismo no Brasil. Rio de Janeiro: Marco Zero, 1987.

SOARES, V. Muitas faces do feminismo no Brasil. In: BORBA, A.; FARIA, N.; GODINHO, T. (Org.). Mulher e política: gênero e feminismo no Partido dos Trabalhadores. São Paulo: Fundação Perseu Abramo, 1998.

VALLE, C. G. 0. Identidades, doença e organização social: um estudo das "pessoas vivendo com HIV e AIDS". Horizontes Antropológicos, Porto Alegre, v. 8, n. 17, p.179-210, jul. 2002.

VALLE, C. G. Sintomas, exames e medicamentos: doença e corpo no caso da epidemia de HIV/ AIDS. In: ENCONTRO ANUAL DA ANPOCS, 27., 2003, Caxambu. Comunicação... Caxambu, 2003. [mimeo].

VELHO, G. Individualismo e cultura. Rio de Janeiro: Zahar, 1981. 